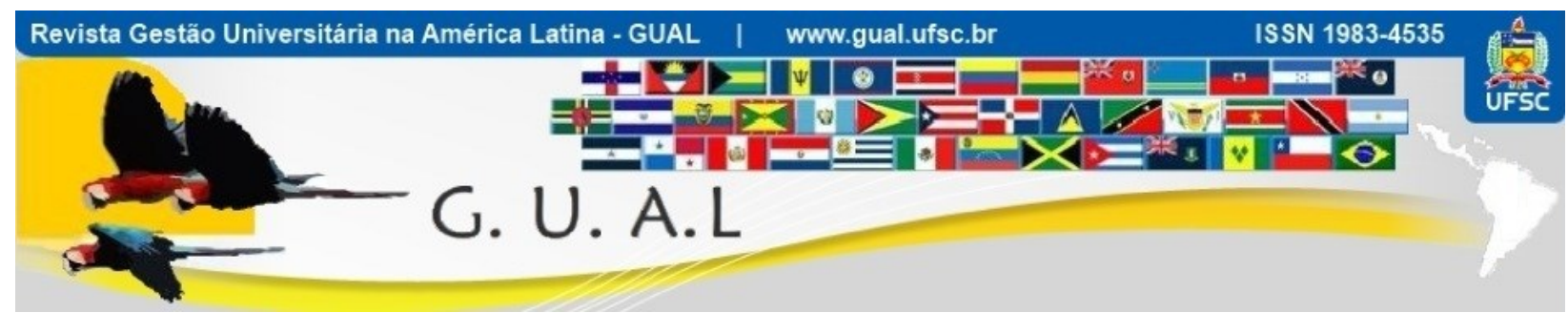

DOI: http://dx.doi.org/10.5007/1983-4535.2013v6n4p216

\title{
CONCEPÇÕES DE UNIVERSIDADE NO BRASIL: UMA ANÁLISE A PARTIR DA MISSÃO DAS UNIVERSIDADES PÚBLICAS FEDERAIS BRASILEIRAS E DOS MODELOS DE UNIVERSIDADE
}

\section{CONCEPTS OF UNIVERSITY IN BRAZIL: AN ANALYSIS FROM THE MISSION OF BRAZILIAN FEDERAL PUBLIC UNIVERSITIES AND UNIVERSITY OF MODELS}

Janice Aparecida Janissek de Souza, Doutora janicejanissek@gmail.com Universidade Federal da Bahia - UFBA

Elder Carlos dos Santos, Graduado eldercarlos2005@yahoo.com.br Universidade Federal da Bahia - UFBA

Angelo Souza Lobo, Graduado angeloslobo@gmail.com Universidade Federal da Bahia - UFBA

Leonardo Cardoso de Melo, Graduado leonardomelo1@live.com Universidade Federal da Bahia - UFBA

Andreia Cerqueira Soares, Graduada cerq.andreia@gmail.com Universidade Federal da Bahia - UFBA

Recebido em 29/novembro/2013

Aprovado em 29/novembro/2013

Sistema de Avaliação: Double Blind Review

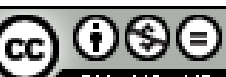

Esta obra está sob uma Licença Creative Commons Atribuição-Uso. 


\title{
RESUMO
}

O objetivo do presente artigo é realizar uma associação entre as principais dimensões que caracterizam a missão de universidades públicas brasileiras com os conceitos centrais que definem os modelos de universidade. Utilizaram-se procedimentos de coleta e análise de dados de forma qualitativa a partir de dados secundários, ou seja, já existentes na literatura. Foram analisadas as missões de oito universidades públicas federais brasileiras disponibilizadas na íntegra no trabalho de Ferreira (2009). Procedimentos de análise de conteúdo foram realizados identificando categorias e subcategorias representativas das ideias mais centrais contidas no texto. Para proceder a associação entre a missão, o perfil do egresso e o modelo de universidade, considerou-se a similaridade de ideias entre as características centrais dos modelos de universidade (humboldtiano, napoleônico e americano) e as subcategorias identificadas na análise de conteúdo da missão. Foi possível constatar que as universidades públicas brasileiras apresentam um modelo híbrido que combina tanto as características que a definem como um centro de construção do saber puro e crítico, isento às pressões externas como as que envolvem a formação de profissionais preparados para atuarem no mercado e as destinadas a atender demandas específicas da sociedade.

Palavras-chave: Concepções universidade. Missões universidades públicas. Gestão universitária.

\begin{abstract}
The aim of this paper is to perform an association between the main dimensions that characterize the mission of Brazilian public universities with the central concepts that define the university models. Procedures for collecting and qualitative data analysis were used from secondary data, in other words, existing in the literature. Were analyzed missions from eight Brazilian federal public universities available in full in Ferreira (2009). Content analysis procedures were performed identifying representative categories and subcategories of the most central ideas in the text. To make the association between the mission, the profile of graduates and the university model, we considered the similarity of ideas between the central characteristics of university models (Humboldtian, Napoleonic and American) and subcategories identified in the content analysis of the mission. It was established that the Brazilian public universities present a hybrid model that combines both the characteristics that define it as a center of construction of critical and pure knowledge, free of external pressures such as those involving the training of professionals prepared to work in the market and designed to meet specific demands of society.
\end{abstract}

Keywords: University conceptions. Public universities missions. University management. 


\section{INTRODUÇÃO}

As Universidades públicas brasileiras vivem um momento muito peculiar de retomada da valorização do ensino superior na área, que pode ser representado principalmente pela ampliação do número destas instituições e pela retomada dos investimentos para a recuperação das condições de infraestrutura, de oferta de vagas e reposição do quadro docente e técnico de seus servidores. Decorrente desta retomada de sua importância no contexto brasileiro surge uma série de pressões para que sua missão como uma organização pública possa ser cumprida. As pressões sociais têm aumentado crescentemente e atingem de forma muito especial as organizações deste setor. Neste sentido, é esperado de todas elas respostas rápidas e efetivas no sentido de melhorarem a prestação de serviços aos cidadãos. A universidade é um tipo de organização complexa, que apresenta um modelo de gestão muito particular e híbrido, que mescla características de uma burocracia mecanizada com as de uma burocracia profissional (Mintzberg, 2003). Grande parte dos desafios e dilemas enfrentados pela universidade advém exatamente de tal hibridismo.

Por ser uma organização complexa, a própria definição deste tipo de organização, a sua missão e os seus objetivos nem sempre são facilmente compreendidos e traduzidos em práticas de gestão.

Em função disso, uma das questões mais debatidas na literatura que explora os conceitos e os modelos de universidade é que não se encontra uma definição clara que possa caracterizar, na essência, a universidade brasileira. Para se compreender tais conceitos e modelos, por sua vez, é necessário recorrer aos diferentes modelos que historicamente orientaram a construção das universidades no mundo. Assim como as características de seu modelo de gestão, o conceito da universidade pública reflete um hibridismo de concepções que mesclam valores e ideais de modelos distintos. Algumas tentativas de se construir uma universidade com um modelo brasileiro não obtiveram o êxito desejado (a exemplo da Universidade de Brasília, por exemplo) e o que se observa na realidade é a influência dos modelos já mais classicamente conhecidos.

A fim de aprofundar o entendimento de quais concepções e modelos norteiam o funcionamento das universidades brasileiras, no presente artigo, busca-se realizar, inicialmente, um levantamento da missão declarada nos planos estratégicos das universidades públicas federais brasileiras. A partir de tal identificação, busca-se construir um mapeamento conceitual dos aspectos que são enfatizados nestas duas dimensões do plano estratégico 
associando tais ênfases aos conceitos centrais que caracterizam os modelos de universidade explorados na literatura sobre o tema, quais sejam, o modelo humboldtiano, o napoleônico e o americano.

Para realizar tal associação, inicialmente, apresenta-se uma síntese conceitual dos modelos de universidade, destacando as suas características mais centrais. Num segundo momento, é realizada uma análise documental dos planos estratégicos das universidades brasileiras, com destaque para o que é declarado em sua missão. Em seguida, apresentam-se as possíveis vinculações existentes entre os conteúdos expressos na missão com os conceitos e concepções centrais que caracterizam os modelos de universidade.

A análise dos planos estratégicos das universidades públicas brasileiras foi realizada com base nos documentos anexados no trabalho de Ferreira (2009) e que apresentam os planos das universidades na íntegra. Para sistematizar os conceitos mais centrais que caracterizam a missão e o perfil do egresso, realizou-se análise de conteúdo, procurando identificar categorias e sub-categorias que ilustrem as ideias envolvidas nestas dimensões do plano estratégico.

Para cumprir os objetivos, no presente artigo apresentam-se, além da parte introdutória um breve histórico do surgimento das universidades no mundo articulando os contextos históricos com a definição dos principais modelos que orientam a concepção da universidade. Uma contextualização do surgimento da universidade brasileira também é delineada. Em seguida são exploradas as análises das missões e do perfil dos egressos e as associações entre os modelos de universidade e a natureza das missões e perfis identificados. As considerações finais são apresentadas como fechamento do artigo.

\section{AS CONCEPÇÕES E MODELOS QUE CARACTERIZAM A NOÇÃO DE UNIVERSIDADE HISTORICAMENTE}

A Universidade do século XXI é reflexo dos conflitos que ocorreram em sua estrutura durante todo seu percurso histórico. As transformações na sociedade colocaram essa instituição diante de crises que impuseram em seu cerne as mais diversas barreiras e conquistas. $\mathrm{O}$ atual modelo de universidade como transmissora de saber teve seu início durante o século XI com a Universidade de Bolonha em 1088. De acordo com Santos e Almeida Filho (2000, p.112) "Essas universidades pioneiras eram abertamente escolásticas, absorvendo o papel social das instituições religiosas que haviam sido sua semente. As protouniversidades substituíram os monastérios". A Igreja ainda detinha o poder nas mais diversas 
instâncias sociais e a universidade era então direcionada a caminhar junto aos ideais divinos, oferecendo cursos de direito e teologia, que possuíam uma estrutura curricular rígida e tinham como principal objetivo educar a elite pensante da época.

No século XV, o domínio foi trocando de mãos e os dogmas da Igreja vão sendo gradativamente postos em questão. O capitalismo entra aí como um grande propulsor do regime pós-escolástico. As escolas médicas foram incorporadas ao panteão universitário, sendo que para Santos e Almeida Filho (2008, p.115) “a emergência do racionalismo iluminista determinou a agregação de centros de formação científica, inicialmente disfarçados como Faculdades de Filosofia, chamados de faculdades inferiores". A formação na área de tecnologias ficara fora das universidades e, era representado apenas pelas escolas militares e iniciativas estatais como a escola de Sagres para as artes náuticas.

Para Pereira (2009), o que conhecemos hoje como universidade moderna tem sua configuração e seus princípios iniciados em dois marcos principais, anteriores aos modelos mais clássicos de análise das universidades, a saber: a Revolução Francesa de 1788 e as ideias de Kant, expressas principalmente em seu livro “O Conflito das Faculdades”, de 1798.

A Revolução Francesa promoveu transformações conjunturais nas universidades e consagrou como definitivo a participação do Estado no controle desta instituição. A derrubada da hegemonia religiosa deixou o terreno fértil para o surgimento de novos modelos. Segundo Paula $(2009$, p.72), tais modelos eram o modelo napoleônico, para formar quadros para o Estado e o de Berlim, com ênfase na integração entre ensino, pesquisa e na busca da autonomia intelectual diante do Estado e da Igreja”. Na França nasceu um modelo que propunha o distanciamento entre os centros de pesquisa e as "grandes escolas" que eram voltadas para o ensino e a formação profissional. Já na Alemanha, Humboldt traz outra proposta para a Universidade, representada pela Universidade de Berlim (criada em 1810), e cuja principal influência pode ser encontrada no relatório de Guillermo Humboldt:

Destacar a importância da pesquisa como função primordial da universidade, ao lado do ensino, concebendo a indissociabilidade do ensino, da pesquisa e da formação como característica essencial da Universidade, ao lado da universalidade de campos de conhecimento, garantida pela centralidade do papel desempenhado pela Faculdade de Filosofia, Ciências e Letras como órgão articulador, por excelência, dos diversos campos do saber. (PAULA, 2009, p.75)

No que tange a contribuição de Kant, Pereira (2009) assevera que "em sua obra, dá início e substrato à produção dos discursos alemães de Fichte, Schleirmacher, Schelling e 
Humboldt sobre a Universidade de Berlim” (p. 42). Estes autores seriam favoráveis às proposições kantianas sobre o conflito entre saber instituído e investigação filosófica que demarcariam a universidade moderna. Todos estes autores concordam na visão da universidade como local onde tendências, aparentemente, opostas coexistem. Isto não se verifica apenas nas formas de construção do saber, mas também nas suas formas de aplicação como o citado conflito entre a universidade especulativa e a universidade profissional (Pereira, 2009). Em virtude do que foi mencionado, é notório o mérito de Kant por apontar as categorias que implicariam crises à universidade moderna. A autora ainda traz as categorias de Kant (1993): Estado, povo, verdade, linguagem, reflexão, determinação, autonomia, história e progresso.

No modelo francês, também conhecido como napoleônico, a perspectiva é funcionalista. Há segmentação institucional entre as écoles e as instituições dedicadas à pesquisa (Caraça et all, 1996). Embora o modelo francês não negligencie a pesquisa, a primazia é pelo ensino que é ministrado nessas universidades, que seriam mais como grandes conglomerados de faculdades independentes academicamente.

Já o modelo de Universidade trazido por Humboldt, defendia maior autonomia das universidades diante das pressões externas, tais como do Estado e da Igreja. Com isso, elevou o status da pesquisa num patamar nunca antes alcançado e defendeu a ideia de indissociabilidade entre ensino, pesquisa e formação.

Neste mesmo momento emergia na Inglaterra, que era o maior centro industrial da época, outro modelo, não com tanta força como o modelo humboldtiano, mas com um pragmatismo que viria a influenciar e modificar as visões tradicionais, à medida que explodia o modo do capital e que este necessitava urgentemente de qualificação da mão de obra, para atender as demandas do país. Tem-se no modelo inglês de universidade um paradigma idealizado na personalidade, isto é, "mais do que a transmissão de conhecimento, interessa-lhe a formação do caráter e da personalidade, numa perspectiva que, de acordo com os conceitos contemporâneos, pode-se apelidar de educação liberal" (Caraça et all, 1996, p. 1224). Esse foi o modelo adotado em Oxford e Cambridge, além de demonstrar semelhanças com as concepções de Humboldt acerca da universidade. Com a crescente importância dada à educação nas colônias, os ingleses colaboraram para o surgimento da grande força emergente do século XX, a universidade ou os colégios dos EUA. 
Entra também no bojo dessa peleja teórica a dissidência entre os que comungam a ideia de uma universidade especulativa e dos que pactuam a ideia de uma universidade profissional. Essas concepções em muito se assemelham às duas correntes ideológicas principais - idealista e funcionalista - trazidas por Dréze e Debelle (1983, apud Pereira, 2009) e que caracterizariam os modelos de universidade ocidental. Na corrente Funcionalista, a universidade seria, principalmente, uma Instituição instrumental de formação profissional, coletiva, sociopolítica e socioeconômica. Esse seria o modelo desenvolvido na França e nos países socialistas. Além disso, seu controle seria externo e ditado pelo Mercado e Estado. Neste sentido, aproxima-se mais ao modelo francês/napoleônico. Na concepção Idealista, fundamentada no postulado de uma educação geral voltada para o desenvolvimento do intelecto; ensino e pesquisa como núcleos centrais; liberdade e autonomia acadêmicas para a produção de conhecimento puro, verdadeiro e independente de influências externas. Neste sentido, pode-se dizer que se aproxima ao modelo humboldtiano ou alemão. Para esses autores, essas seriam as matrizes conceituais do que viria a ser chamado de universidade moderna.

O modelo de universidade americano surge inicialmente "durante a colonização dos Estados Unidos por grupos religiosos nos séculos XVII e XVIII e incentivadas pela metrópole" (Ferreira, 2009, p. 109). Os norte-americanos pretendiam manter os valores da religião protestante, oriundos da Inglaterra e banidos devido à perseguição religiosa, e levaram essa ideia para as universidades. Tinha a meta de atender as elites locais e de formação de mão de obra para o estado e clero, assim como o modelo Francês. Mas a partir do século XIX com a fundação da Universidade de John Hopkins inspirada no modelo alemão, novos valores são agregados e começa a se formar um modelo novo, nascido da fusão dos clássicos e com a característica de ser fortemente ligado à comunidade, o que contribuiu para o desenvolvimento da agricultura da época "e, mais tarde, das ciências da engenharia necessárias para o crescimento industrial, designadamente a engenharia química e, posteriormente, a engenharia electrotécnica" (Caraça et all, 1996, p. 1225). A complexificação do capitalismo, que requeria concepções flexíveis e cujo principal foco estava no desenvolvimento nacional e produção de novas tecnologias, uniu, segundo Paula (2009, p.78), “aspectos ideais (ensino e pesquisa) aos funcionais (serviços), estruturando-se de tal maneira que possa ajustar-se às necessidades da massificação da educação superior e da sociedade de consumo". 
Essa forte ligação da universidade americana com a comunidade vai favorecer a função de ligação à sociedade, como afirma Caraça et all (1996, p. 1225). Ainda segundo o autor, o casamento entre a necessidade das universidades mostrarem sua relevância social devido às críticas de serem instituições elitistas e a necessidade das empresas aproximarem-se de fontes de conhecimento e de instituições relevantes para o processo de inovação - papel que as universidades americanas vinham exercendo com excelência -, são peças fundamentais na consolidação da extensão universitária. No Brasil, a inserção desse terceiro elemento do tripé (extensão universitária), só veio ocorrer com a Reforma Universitária estabelecida pela Lei $n^{\circ} .5 .540$ de 1968.

Com essa breve revisão da evolução conceitual da universidade e as mudanças que viriam a culminar na universidade como a conhecemos atualmente, observa-se, portanto, uma mutabilidade adaptativa da universidade dita moderna ao longo do tempo que visa ajustar-se às demandas de seus contextos sociopolíticos. Para sintetizar o que foi nesta sessão explorado, a Figura 1 apresenta principais características dos três modelos referidos.

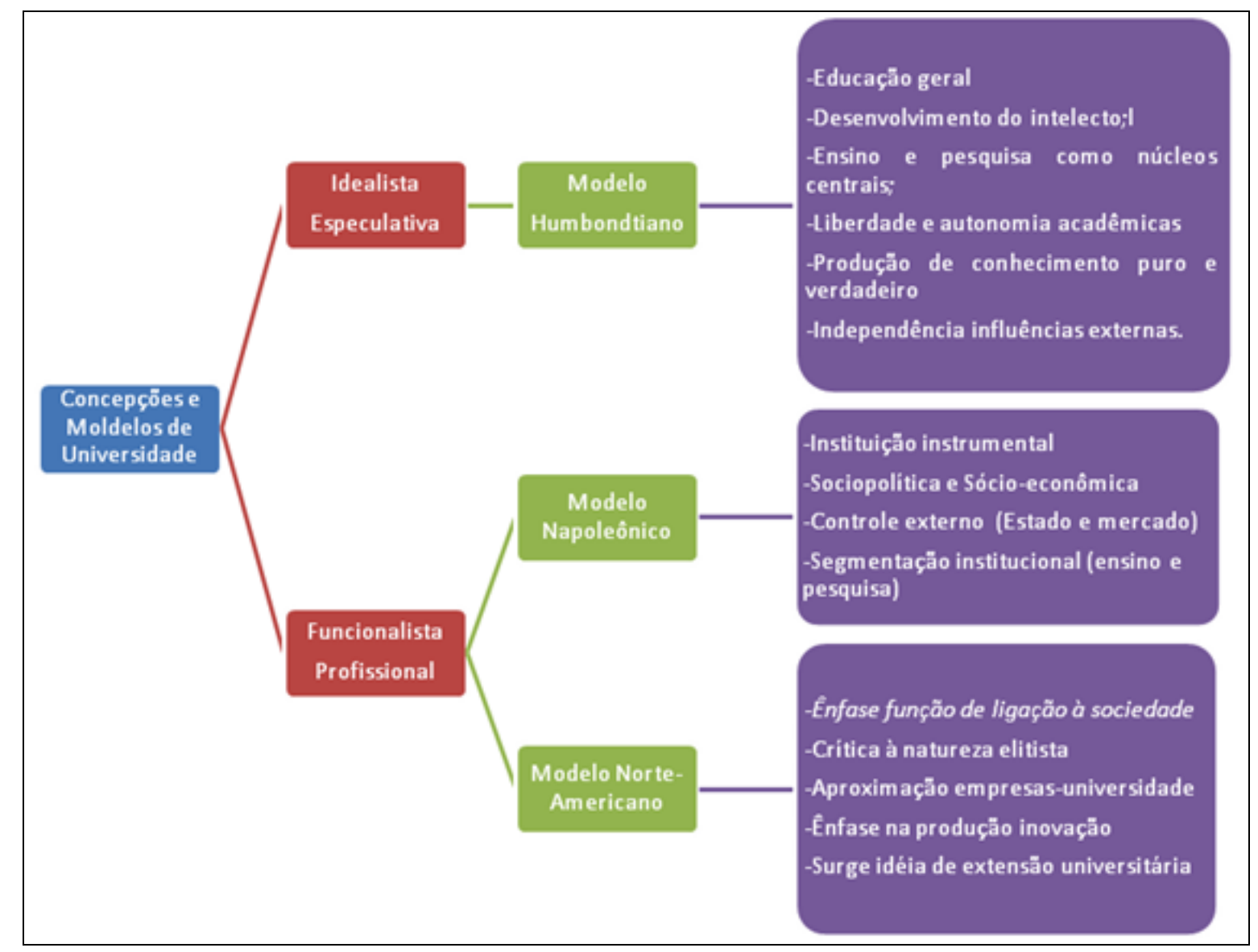

Figura 1 Esquema dos três modelos de universidade.

Fonte: (Resumo das ideias apresentadas). 
Após discutirmos brevemente as características dos modelos que fundamentam a noção do que é uma universidade, a seguir exploram-se os aspectos que marcaram o surgimento da universidade brasileira.

\section{O SURGIMENTO DA UNIVERSIDADE BRASILEIRA}

No início do período em que o Brasil era uma colônia de Portugal, o ensino superior era destinado apenas para a elite e esta obtinha a sua formação na Europa, mais especificamente em Portugal, na Universidade de Coimbra. Esta universidade apresentava grande influência da Igreja, sendo comandada pela Companhia de Jesus que se mantinha fiel ao modelo escolástico e aos ensinamentos medievais. Nela se forneciam os graus de doutor apenas em Direito, Teologia e Medicina.

Tal realidade começou a ser alterada quando surge, na Bahia, o primeiro curso de educação superior na Escola de Cirurgia do Hospital Real Militar, fundada por D. João VI em 1808, logo após a vinda da família real e da corte que fugia das guerras napoleônicas.

Com a independência do Brasil surgiram novas instituições. Entretanto, os portugueses não incentivaram a expansão de tais instituições, ficando a sua existência restrita a algumas academias de ensino. Essa realidade começa a mudar no Início do século XX, quando as escolas superiores vindas da França passam a influenciar de forma significativa a formação das universidades brasileiras. Neste contexto, a Universidade Federal da Bahia surge como uma das primeiras a se revelar uma semente universitária, como argumentam Santos e Almeida Filho (2008, p.130):

[...] a antiga Faculdade de Medicina da Bahia, nossa semina mater, revelouse, desde cedo, uma verdadeira universidade. Por um lado, a oferta pedagógica sempre foi diversificada, com cursos superiores de Cirurgia, Medicina, Farmácia, Odontologia e Obstetrícia, posteriormente desdobrando-se em Psicologia, Enfermagem e Nutrição. Por outro lado, a instituição já realizava efetiva integração de ensino, pesquisa e compromisso social.

No entanto, a história oficial da nação diz que as primeiras universidades surgiram na década de 30. A USP (Universidade de São Paulo) que seguiu o modelo alemão e a UDF (Universidade do Distrito Federal) que propunha um modelo nacionalista com a ideia de construir um formato de universidade 'tupiniquim', para resgatar a identidade nacional, podem ser consideradas as primeiras universidades brasileiras. A disseminação das universidades públicas, no entanto, iniciou-se somente a partir do fim da era Vargas. 
A história da consolidação das instituições públicas de ensino superior no Brasil foi marcada por alguns fatos e momentos especiais que influenciaram de forma significativa o seu funcionamento. Um dos marcos importantes foi a criação da Universidade de Brasília (UnB), durante o governo do presidente Juscelino Kubitschek. A fim de apoiar a inovação e estimular o projeto de nação, o referido presidente convidou grandes pensadores da época, tais como Anísio Teixeira e seu discípulo Darcy Ribeiro, para planejar tal universidade considerada por Santos e Almeida Filho (2008, p.135) "o primeiro centro acadêmico de um novo modelo civilizatório para o Brasil".

Outra mudança importante que marca a história da universidade pública brasileira foi o início da influência do modelo americano de universidade. A partir do golpe militar de 1964, há uma missão de consultores e técnicos norte-americanos que produziram o relatório ATCON (Rudolph Atcon, autor norte-americano). Este relatório continha claramente uma concepção de universidade próprio do modelo vigente nos EUA. Segundo Paula (2009, p.77) “esta concepção será amplamente difundida a partir da Reforma Universitária de 68, atingindo a estrutura organizacional e as finalidades de todas as universidades". Essa reforma trazia a ideia de racionalização, fortalecida por categorias próprias de linguagem tecnicista difundindo termos como eficiência, eficácia, produtividade, etc. $\mathrm{O}$ processo educativo vai se transformando em produto de consumo e as universidades em empresas. O que para Paula (2009, p.78) significa que "ao adotar a forma empresarial, boa parte das universidades procuram atender aos interesses imediatos do setor produtivo, do Estado e da sociedade, produzindo especialistas, conhecimento tecnológico e aplicado, pesquisas de interesse utilitário".

A partir da década de 80 , novas transformações são observadas no funcionamento e no papel das universidades brasileiras. Neste período histórico, caracterizado por um novo contexto político, econômico e social marcado pelas ideias neoliberais, as universidades públicas passam a ter que prestar contas ao estado sobre a sua produção acadêmica no ensino, na pesquisa e na extensão. O Estado, assim cria mecanismos de avaliação docente, departamental e institucional na graduação e na pós-graduação, compelindo-as a apresentarem resultados à sociedade.

Os ideais da reforma de 68 que encarava a universidade como uma empresa privada e, sobretudo como instrumento de aceleração do desenvolvimento, estavam a se concretizar aproveitando a fertilidade do regime democrático que emergia no país, após anos de 
militarismo. O que ocorre daí em diante é uma massificação do ensino superior que nos faz tornar a refletir sobre as crises que atravessam as universidades brasileiras.

Os estudantes que adentram nessas instituições convivem com altas taxas de ociosidade e inadimplência. Todavia é nesta turbulência de fatores que nasce a universidade do século XXI.

A universidade brasileira é uma instituição jovem em termos latinoamericanos e mundiais, nasceu associada aos desafios republicanos do Brasil moderno. Contudo, carrega uma enorme responsabilidade: contribuir para a formação de cidadãos críticos e participativos, pessoas que ajudarão a construir um Brasil mais desenvolvido, justo e democrático (PAULA, 2009, p.83).

As crises que a universidade enfrenta em decorrência das inúmeras transformações em sua dinâmica proporcionam um campo de possibilidades criativas para o futuro desta instituição e para melhor estreitamento desta com as demandas da sociedade. A universidade não é a única a produzir conhecimentos válidos em pesquisa, compartilhando esta tarefa com outras instituições. Santos (2004) considera que quando deixou de ser a única instituição no domínio do ensino superior e na produção de pesquisa, a universidade entrou numa crise de hegemonia. Entretanto o conjunto que legitima as instituições universitárias pós-modernas é justamente a quebra das tradições paradigmáticas criadoras de crises ontológicas, baseadas na ideia de centro único de formação (Hegemônica), com acesso restrito as elites em detrimento da maioria (Legitimidade) e controlada por forças externas tendo pouca autonomia (Institucional), devendo se firmar sob a égide do caráter dialógico com a sociedade, num formato flexível 'nem dominante, nem dominada', com possibilidade de acesso a todos os cidadãos e com autonomia no que tange a sua produção acadêmica e científica.

A meta então é construir, a partir do conflito potencial que está sempre a emergir, novos rumos para a formação universitária, considerando que as mudanças ocorridas nas universidades acompanharam algumas transformações fundamentais na forma de conceber o ensino e no próprio pensamento humano. Corroborando com a ideia de Santos e Almeida Filho (2008), a universidade do futuro será menos hegemônica, mas não menos necessária que o foi nos séculos anteriores. 


\section{PROCEDIMENTOS METODOLÓGICOS}

A presente pesquisa é um estudo de levantamento onde se utilizou procedimentos de coleta e análise de dados de forma qualitativa a partir de dados secundários, ou seja, já existentes na literatura.

Inicialmente, foram identificadas as missões de oito universidades públicas federais brasileiras disponibilizadas na íntegra no trabalho de Ferreira (2009). Em seguida, foi realizada a análise de conteúdo desse material, identificando categorias e subcategorias que traduzissem as ideias mais centrais contidas no texto. Inicialmente, considerou-se para a análise o grupo de universidade como um todo, o que resultou num mapa geral que traduziu as concepções presentes nas missões de todas as universidades públicas. Para proceder a associação entre a missão, o perfil do egresso e o modelo de universidade, considerou-se a similaridade de ideias entre as características centrais dos modelos de universidade (humboldtiano, napoleônico e americano) e as subcategorias identificadas na análise de conteúdo da missão e do perfil do egresso.

\section{ARTICULANDO MISSÕES E CONCEPÇÕES DE UNIVERSIDADE}

Nesta etapa do artigo, busca-se apresentar a associação encontrada entre a análise das missões com os modelos mais clássicos de universidade. Para tanto, inicialmente apresenta-se a análise de conteúdo das missões das universidades pesquisadas identificando as principais categorias e as suas respectivas unidades de análise. Em seguida, tais categorias serão associadas aos principais modelos de universidade.

Quando se pensa na missão de uma organização e qual é a sua importância logo vem à mente a ideia da definição da razão maior para a qual ela foi criada. Ou seja, a missão de uma universidade oferece uma ideia da razão de sua existência. Envolve também uma orientação fundamental para a definição dos seus objetivos os quais devem se desdobrar em ações (práticas de gestão) que efetivamente irão concretizar e traduzir a sua missão. Dessa forma, todas as organizações, independentemente de seu tamanho e natureza necessitam pensar sobre a sua missão.

Para que isto ocorra, no entanto, não basta que a missão seja planejada e registrada em documentos. Ela precisa ser amplamente socializada, de modo que todas as pessoas que nela atuam saibam e a reconheçam como legítima. 


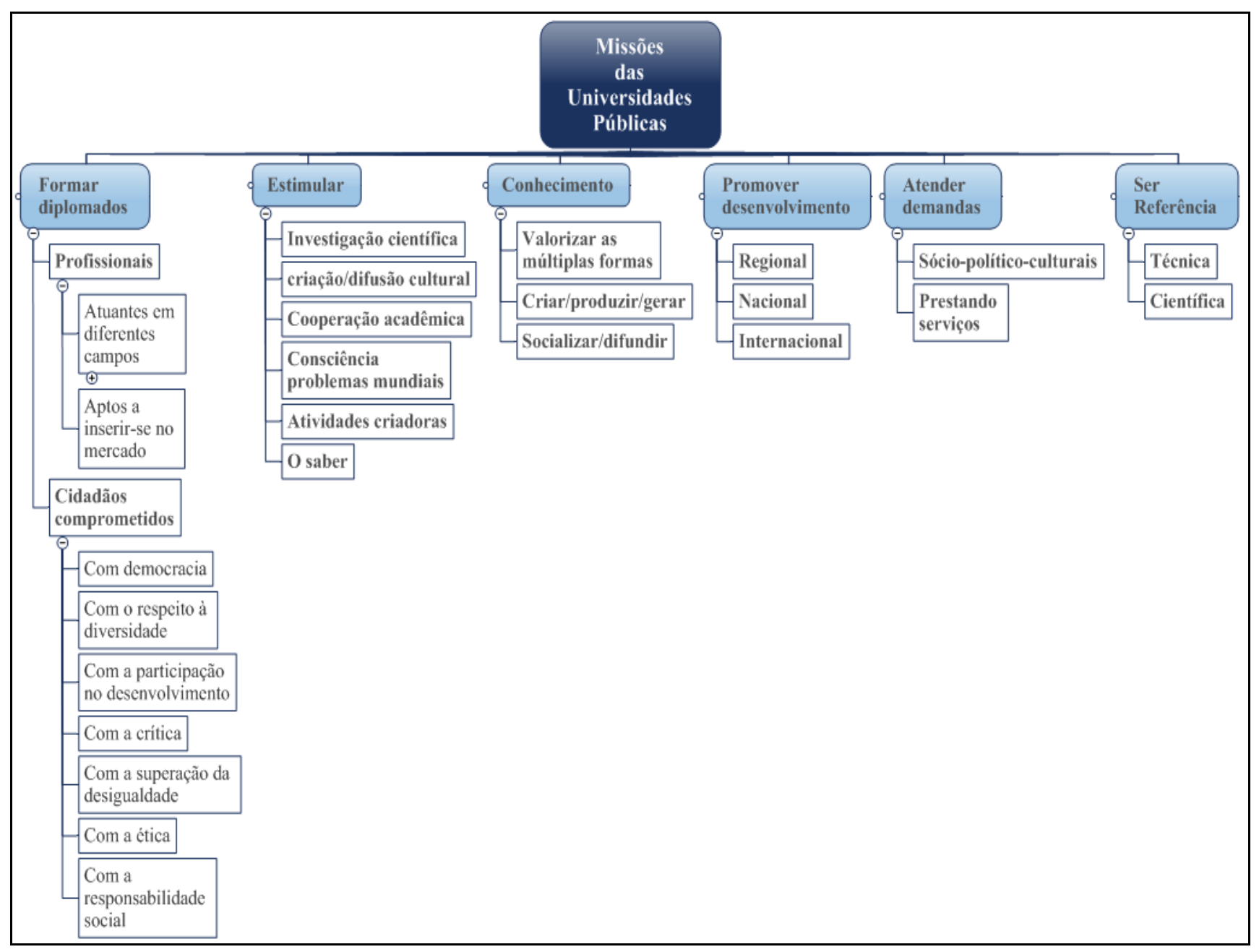

Figura 2 Categorização das missões das universidades.

Fonte: Análise de conteúdo das missões da universidade.

No caso da universidade, o perfil declarado do egresso de seus cursos espelha um resultado, algo que é construído a partir da missão da universidade. São dois polos de uma mesma linha, ou seja, a missão marca o início e o perfil do profissional formado é o final de todo o processo educacional que foi ou deveria ter sido orientado pela missão da organização. É possível, ainda, considerar que tanto o perfil do egresso quanto a missão da universidade estão inseridos em um contexto maior que é a concepção de universidade que caracteriza ou que orienta de forma mais ampla o funcionamento da organização, ou seja, os modelos de universidade. Conforme se ressaltou nas sessões anteriores, é difícil observar-se a existência de um modelo único de universidade que tenha sido adotado no contexto brasileiro. A literatura aponta um hibridismo neste sentido. Mesmo assim é possível identificar a predominância de um modelo, embora tal modelo não se constitua em algo puro. 
A primeira etapa da análise consistiu na categorização das principais ideias contidas nas missões das universidades públicas brasileiras. A Figura 2 ilustra uma síntese da análise de conteúdo que foi realizada a partir das missões declaradas das universidades consideradas no estudo.

Uma primeira análise da Figura 2 revela que duas categorias agrupam, de forma mais significativa, as ideias apresentadas nas missões das universidades. A primeira delas expressa uma das funções clássicas das universidades que é formar diplomados. Tal formação permite aos graduados atuarem em profissões específicas, em diferentes campos do saber e, desta forma, legitimam a inserção e a atuação de profissionais no mercado de trabalho. Para além da missão de formar profisssionais, a universidade também deve preparar tais profissionais para atuarem como cidadãos. Neste sentido, a noção de que significa ser cidadão comprometido assume uma ampla gama de aspectos, desde o comprometimento com questões políticas e sociais, tais como a democracia, a superação das desigualdades e a participação no desenvolvimento até o comprometimento com a crítica, com o respeito à diversidade, com a ética e com a responsabilidade social. É possível observar, a partir dos conteúdos expressos nesta categoria de formar diplomados tanto uma visão de universidade voltada para a formação de quadros pensantes e cidadãos críticos, próprios de um modelo mais humboldtiano, assim como uma visão mais voltada à formação de quadros para atuarem no mercado de trabalho, modelo mais conectado com a visão napoleônica de universidade. Neste sentido, dentro de uma mesma categoria é possível identificar um hibridismo de concepções, retratando modelos distintos de universidade expressos nas missões das universidades.

A segunda categoria mais densa que agrupa ideias sobre a missão da universidade diz respeito a sua função de estimular uma série de questões. Neste sentido, a universidade é considerada como uma fonte propulsora da investigação científica, da cooperação acadêmica, das atividades que visam à criação de um modo geral e também da cultura, da consciência dos problemas mundiais e do saber.

As questões relacionadas com a valorização, produção e difusão do conhecimento aparecem também com destaque nas missões da universidade. Essa categoria traduz uma importante dimensão que sempre está presente quando se discute a função da universidade. Ela sempre foi considerada o lugar privilegiado onde a produção de conhecimento deve ocorrer, principalmente a partir de suas atividades de pesquisa. Ao se conceber que a universidade deve valorizar as múltiplas formas de conhecimento, uma questão que faz parte 
das discussões acerca do papel da universidade é se o conhecimento que nela é produzido deve se voltar para atender demandas sociais específicas, solucionando problemas práticos do dia-a-dia dos cidadãos ou se deve ser essencialmente crítico, puro sem vinculação direta com demandas específicas. No modelo humboldtiano, a universidade tem como missão fundamental a produção do conhecimento crítico, voltado para a reflexão dos problemas sociais, sem a sua natureza aplicada. No modelo Napoleônico, essa função passa a ser entendida como tendo uma estreita vinculação com as demandas sociais, portanto, com o conhecimento aplicado. A implicação destas duas concepções reflete-se na tradicional discussão sobre o papel da universidade, ou seja, de um lado se critica o isolamento social de uma universidade que se preocupa com a produção do conhecimento puro ou então, que a universidade que se preocupa em produzir conhecimento útil socialmente estaria à mercê de interesses de determinados grupos, organizações ou segmentos sociais.

Outra questão que emerge desta missão nos leva a refletir sobre a questão da difusão do conhecimento produzido na universidade, independentemente da natureza que ele assuma, mais puro ou aplicado. Normalmente, muito do que é produzido no contexto das universidades permanece inacessível e sem difusão social. Neste sentido, a crítica é de que a universidade precisa aprimorar muito seus canais de comunicação com a sociedade no sentido de divulgar e socializar mais aquilo que se produz por meio da pesquisa científica. Maior investimento na produção de conhecimento voltada para demandas específicas, por meio de parcerias com outros setores da sociedade seria uma forma de aplicar tais conhecimentos.

A promoção do desenvolvimento, seja ele regional, nacional e até mesmo internacional, é outra categoria que aparece nas missões da universidade. Neste sentido, duas regiões aparecem enfatizadas: a Amazônia e a região nordeste. Ao se conceber que a universidade tem um papel ativo na promoção do desenvolvimento, fica implícito também que ela tem um papel ativo no atendimento de demandas sociais, seja nas questões sociais, políticas e culturais ou também na prestação de serviços técnicos. Neste sentido, a missão das universidades também contempla que ela deve ser a referência técnica e científica da sociedade, ou seja, o lugar, por excelência, onde a competência e o exemplo nestas duas dimensões devem ser buscados.

De posse do entendimento das principais ideias que configuram as missões das universidades e a partir dos principais conceitos que estruturam os modelos de universidade 
mais clássicos tratados na literatura da área é possível estabelecer uma associação entre estes elementos a fim de caracterizar como são adotados os modelos de universidade.

A Figura 3 sintetiza as associações que podem ser estabelecidas.

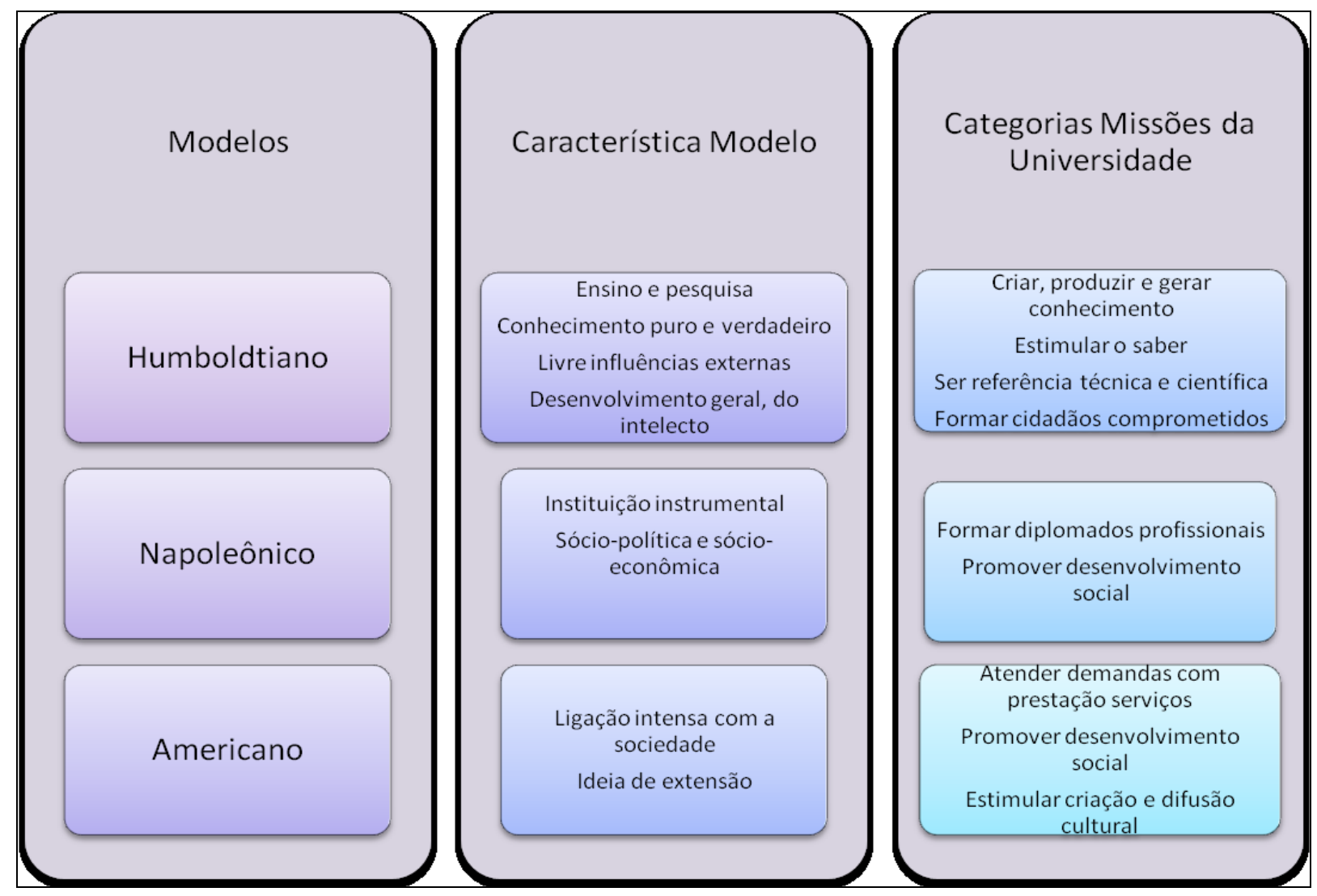

Figura 3 Relação entre missões e modelos.

Fonte: Análise de conteúdo das missões e dos modelos de universidade.

Conforme pode ser observado no Quadro 3, as universidades públicas pesquisadas se apropriam das concepções dos três modelos mais clássicos. Embora haja uma predominância da presença dos modelos napoleônico e americano, enfatizando, portanto a necessidade de a universidade estar aberta às influências externas e responder às demandas da sociedade, podese dizer que as universidades pesquisadas também valorizam a produção do conhecimento mais crítico e isento e, além da formação profissional voltada para a atuação no mercado, também existe a preocupação com a formação de cidadãos comprometidos. Um modelo híbrido, portanto, orienta as políticas e práticas das universidades públicas brasileiras.

Tal constatação confirma o que a literatura da área tem apontado, ou seja, não se pode considerar que exista um modelo próprio, hegemônico de universidade brasileira, mas ela é reflexo das diversas influências que recebeu ao longo da história de sua formação. Assim, no 
contexto da universidade, convivem segmentos que representam concepções diferentes, sejam aquelas que defendem as políticas e práticas voltadas para a produção do conhecimento puro e crítico, sejam os que valorizam a prestação de serviços voltados para as demandas do mercado e da sociedade.

As diversas tentativas de encontrar um modelo próprio de universidade no Brasil parecem não ter resistido a forte influência das concepções mais tradicionais que fundamentaram o surgimento deste tipo de instituição. Sua identidade, portanto, envolve uma associação de concepções e pode explicar, em parte, os embates que se travam no interior de suas Escolas e Faculdades quando se trata de defender o papel da universidade na sociedade atual.

\section{CONSIDERAÇÕES FINAIS}

A partir dos objetivos propostos para desenvolver o presente estudo pode concluir, inicialmente, que a missão das universidades pesquisadas envolve um conjunto eclético de dimensões que representam focos prioritários que orientam suas políticas e práticas de gestão acadêmicas e administrativas. Neste sentido, pode-se observar um conjunto de dimensões representam ênfases voltadas para: a formação de profissionais e de cidadãos comprometidos com as questões sociais; a produção e difusão do conhecimento; as questões relacionadas com o desenvolvimento nacional, regional e internacional; estimular e ser referência em aspectos como a investigação científica, as atividades criativas, a criação e difusão cultural e a consciência dos problemas mundiais.

A associação das dimensões extraídas da análise de conteúdo das missões nos permite concluir ainda que não existe um modelo único que predomine como base para a definição de tais missões. Assim, a convivência com as concepções do modelo humboldtiano, do napoleônico e do americano indicam que a universidade pública brasileira apresenta um modelo híbrido. Não é possível identificar assim, uma concepção pura, ou própria de um modelo brasileiro quando o foco de análise são as missões declaradas das universidades.

Tal hibridismo na forma de se conceber a universidade implica dizer que ela se move em função de duas grandes forças, ou seja, aquela que se concentra na produção do saber puro, autônomo e imune às pressões externas e aquela que foca na produção de um conhecimento sensível às demandas específicas, sejam elas regionais, nacionais e/ou internacionais. Além disso, é bastante presente a ideia que a universidade é um centro de 
referência para a sociedade tanto no que se refere aos aspectos científicos quanto técnicos, pressupondo assim, uma relação de mão-dupla entre a sociedade e a universidade.

Para finalizar, é importante destacar que a análise aqui apresentada tem um caráter exploratório e a constatação do hibridismo do modelo de universidade brasileiro requer investigações mais aprofundadas que enfoquem outras variáveis de investigação, tais como as políticas e práticas efetivas de gestão acadêmica e de gestão das universidades. Isto porque, os dados utilizados no presente estudo são de natureza secundária e se referem àquilo que é declarado pelas universidades em seus documentos oficiais. Sabe-se que entre aquilo que se planeja nem sempre é possível colocar em prática.

\section{REFERÊNCIAS}

CARAÇA, J. M. G.; CONCEIÇÃO, P.; HEITOR, M. V. Uma perspectiva sobre a missão das universidades. Análise Social, v. 139, n. 5, p. 1201-1233, 1996. Disponível em: $<$ http://analisesocial.ics.ul.pt/documentos/1223396575R0tIQ8js9Iy17FX8.pdf $>$. Acesso em: 18 jul. 2012.

DRÉZE, J.; DEBELLE, J. Concepções da universidade. Fortaleza: EdUFCE, 1983. 131p. Apud PEREIRA, E. M. A. A universidade da modernidade nos tempos atuais. Avaliação (Campinas), Sorocaba, v. 14, n. 1, p. 29-52, Mar. 2009. Disponível em:

$<$ http://www.scielo.br/pdf/aval/v14n1/a03v14n1.pdf>. Acesso em: 23 jul. 2012.

FERREIRA, S. A universidade do século XXI: concepções, finalidades e contradições. 2009. 305 p. Tese (Doutorado em Educação) - Faculdade de Educação, Universidade Federal de Goiás, Goiânia, 2009.

KANT, I. Conflito das faculdades. Lisboa: Edições 70, 1993. 144p. Apud PEREIRA, E. M. A. A universidade da modernidade nos tempos atuais. Avaliação (Campinas), Sorocaba, v. 14, n. 1, p. 29-52, Mar. 2009. Disponível em:

$<$ http://www.scielo.br/pdf/aval/v14n1/a03v14n1.pdf $>$. Acesso em: 23 jul. 2012.

MINTZBERG, H. Criando organizações eficazes: estruturas em cinco configurações. 2.ed. São Paulo: Atlas, 2003. 336p.

PAULA, M. F. A formação universitária no Brasil: concepções e influências. Avaliação (Campinas), Sorocaba, v. 14, n. 1, p. 71-84, Mar. 2009. Disponível em:

$<$ http://www.scielo.br/pdf/aval/v14n1/a05v14n1.pdf>. Acesso em: 17 jul. 2012.

PEREIRA, E. M. A. A universidade da modernidade nos tempos atuais. Avaliação

(Campinas), Sorocaba, v. 14, n. 1, p. 29-52, Mar. 2009. Disponível em:

$<$ http://www.scielo.br/pdf/aval/v14n1/a03v14n1.pdf >. Acesso em: 23 jul. 2012.

SANTOS, B.S.; ALMEIDA FILHO, N. A Universidade no século XXI: para uma universidade nova. Coimbra: Almedina, 2008. 184p. 